\title{
Tendências do
}

\section{empreendedorismo no Brasil}

\section{A PESQUISA GLOBAL ENTREPRENEURSHIP MONITOR É UMA DAS PRINCIPAIS FONTES DE DADOS SOBRE AS CARACTERÍSTICAS DA ATIVIDADE EMPREENDEDORA NO BRASIL. NESTE ARTIGO, COMENTAMOS ALGUNS DOS PRINCIPAIS RESULTADOS DA SUA ÚLTIMA EDIÇÃO}

\footnotetext{
MARCELO MARINHO AIDAR, professor da FGV-EAESP, marcelo.aidar@fgv.br
}

“O Brasil é um país de empreendedores". Essa é uma frase que ouvimos com certa frequência e que já se tornou um chavão. Certamente, a afirmação tem a sua razão de existir: em 2009, algo próximo de 30 milhões de brasileiros estavam envolvidos em algum tipo de empreendimento em estágio inicial. Além disso, a proporção que essas pessoas representam na população do país - perto de $15 \%$ - parece estar crescendo nos últimos anos, uma vez que sua média histórica é da ordem de $12 \%$.

\section{A taxa de empreendedorismo no Brasil deu um salto em 2009 e atingiu o maior valor registrado desde 0 início da pesquisa}

Esses são alguns dos dados da pesquisa Global Entrepreneurship Monitor (GEM) 2009, divulgada em abril deste ano. A pesquisa é realizada anualmente, desde 1999, e mede a intensidade e as características do empreende- dorismo em diversos países, a fim de avaliar e apoiar as políticas de incentivo ao empreendedorismo nos diferentes contextos nacionais. Ela é conduzida por um consórcio entre a London Business School, da Inglaterra, e o Babson College, dos EUA. A última edição foi realizada em 54 países, que representam juntos 95\% do PIB mundial e dois terços da população global. O Brasil participa desde 2000, com dados coletados pelo Instituto Brasileiro de Qualidade e Produtividade (IBQP) e com acompanhamento do Sebrae.

TAXA DE EMPREENDENDORISMO. Um dos resultados da última edição da GEM, no que se refere ao Brasil, é o aumento registrado na atividade empreendedora em 2009, comparativamente aos anos anteriores. Para entendermos esse resultado, convém primeiramente entendermos de que forma essa taxa é calculada. A metodologia utilizada parte do pressuposto de que a atividade empreendedora é um processo, e, como tal, considera que as pessoas responsáveis por um empreendimento, formal ou informal, 
passam por quatro estágios distintos e sequenciais, representados na figura 1 .

O primeiro deles é o dos chamados "empreendedores potenciais", isto é, pessoas que estão considerando a possibilidade de iniciar um empreendimento, mas não o fizeram ainda porque estão concebendo o negócio ou reunindo os conhecimentos e habilidades necessários. A fase seguinte é a dos "empreendedores nascentes", ou seja, aqueles que já iniciaram o negócio, mas ainda não retiraram nenhum tipo de remuneração. Quando o negócio já remunerou o proprietário, mas ainda não completou 42 meses de atividade, considera-se que ele está no estágio de "empreendedor novo". Finalmente, a partir do $43^{\circ}$ mês, o empreendedor é considerado "estabelecido". O critério para o ponto de corte aos 42 meses baseia-se, principalmente, no fato de que é até esse ponto que, historicamente, costuma se dar a maior incidência de mortalidade dos empreendimentos.

Dado esse modelo de quatro estágios, a pesquisa calcula duas proporções. A primeira é a chamada Taxa de Empreendedores Nascentes, definida como a porcentagem da população entre 18 e 64 anos que se encontra envolvida na estruturação de um empreendimento em fase nascente, isto é, no segundo dos estágios representados na figura 1. A segundaéa Taxa de Empreendedores Novos, isto é, a porcentagem da população que se encontra no estágio seguinte. A soma dessas duas proporções resulta no principal resultado da pesquisa, que é a chamada Taxa de Empreendedores em Estágio Inicial (TEA).

UM SALTO EM 2009. O gráfico 1 apresenta a evolução da TEA no Brasil na década de 2000. Observa-se no gráfico que, embora ao longo do

\section{FIGURA 1 - ESTÁGIOS DA ATIVIDADE EMPREENDEDORA E CRITÉRIO DE CÁLCULO DA TEA}

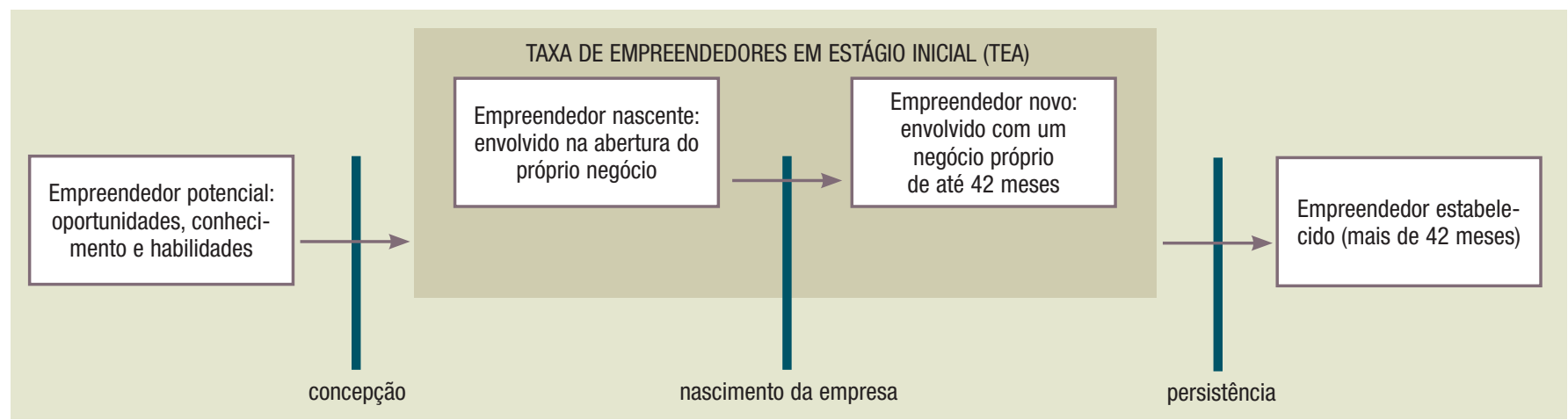

FONTE: PESQUISA GEM 


\section{$\nabla$ MURAL DE PESQUISA}

GRÁFICO 1 - EVOLUÇÃO DA TAXA

DE EMPREENDEDORES EM ESTÁGIO INICIAL (TEA) NO BRASIL

(\% sobre a população entre 18 e 64 anos de idade)

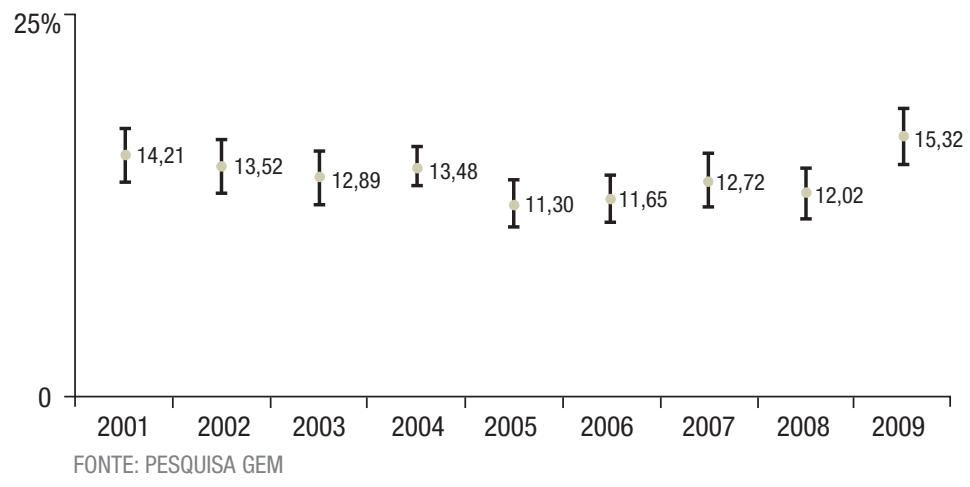

GRÁFICO 2 - EMPREENDEDORISMO

POR NECESSIDADE E POR OPORTUNIDADE

(\% sobre a população entre 18 e 64 anos de idade)

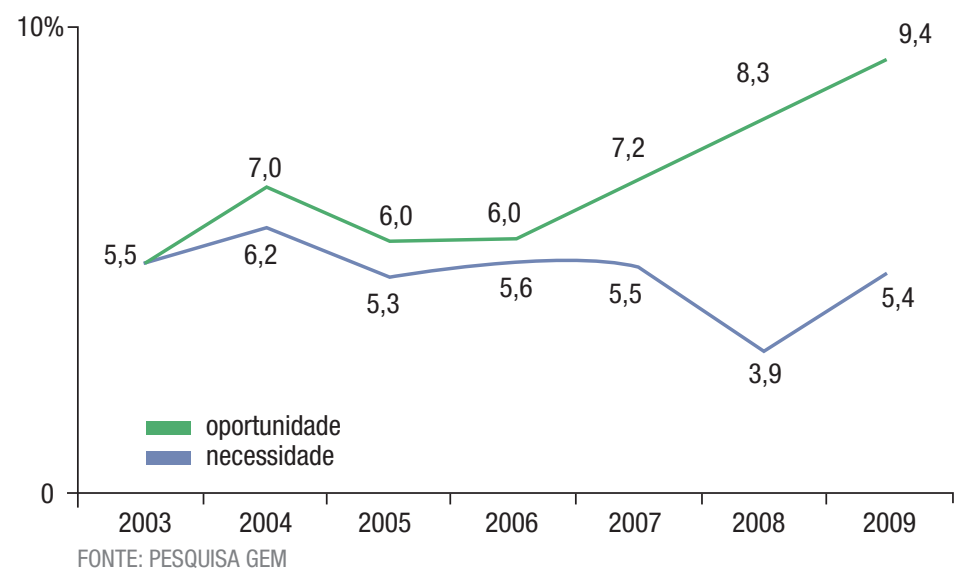

tempo ela tenha se mantido relativamente estável - em torno de 13,5\% entre 2001 e 2004, e de $12 \%$ entre 2005 e 2008 -, em 2009 ela saltou para o nível recorde de $15,32 \%$. No gráfico, as barras verticais representam a margem de erro da pesquisa, que em 2009 se baseou em amostra de 2 mil pessoas.

O relatório da pesquisa GEM 2009 ressalta a necessidade de continuar acompanhando essa taxa nos próximos anos a fim de verificar a sustentação, ou não, desse salto registrado na TEA. De qualquer forma, é possível ressaltar que o aumento na TEA reflete um salto considerável na proporção de empreendendores nascentes (fase 2 da figura 1), já que a proporção de empreendendores novos (fase 3) permaneceu praticamente inalterada em relação a 2008, conforme pode ser visto na tabela 1 .

\section{O empreendedorismo por necessidade parece estar cedendo espaço ao empreendedorismo por oportunidade}

Um dos motivos que podem ser atribuídos a esse crescimento na Taxa de Empreendedores Nascentes é o fato de 2009, sobretudo nos três primeiros trimestres, ter sido um ano de incertezas econômicas, em função das possíveis consequências da crise econômica mundial iniciada em 2008. Diante da ameaça de perda de emprego formal, muitos brasileiros podem ter abraçado o empreendedorismo como forma de proteção. 
Essa explicação, contudo, ainda merece ser refinada à luz dos resultados das pesquisas futuras. De qualquer forma, caso esses novos negócios nascentes surgidos em 2009 efetivamente vinguem e consigam remunerar seus proprietários, é de se esperar que tenhamos um considerável crescimento na Taxa de Empreendedores Novos na próxima edição da GEM.

\section{NECESSIDADE VERSUS OPORTUNIDADE.}

Outro relevante aspecto medido pela GEM diz respeito às motivações por trás da abertura de negócios. A pesquisa leva em conta que uma parcela dos empreendedores é movida "por necessidade", isto é, é impelida a abrir um negócio por falta de opção de subsistência, ao passo que outra parcela é movida "por oportunidade", isto é, opta por empreender por vocação, em resposta a oportunidades ou nichos de negócios identificados no mercado. Desnecessário dizer que os empreendimentos dessa segunda categoria costumam ser mais planejados e consistentes, e têm maiores chances de sucesso e sobrevivência do que os da primeira.

Nesse particular, o que a pesquisa GEM 2009 permite avaliar é uma clara melhora na qualidade do empreendedorismo brasileiro nos anos recentes. Na composição da atividade empreendora no Brasil, nota-se uma tendência à diminuição dos empreendimentos por necessidade e um aumento nos de oportunidade (gráfico 2). Se há relativamente poucos anos os dois grupos tinham importância semelhante, nota-se uma consistente expansão na incidência de empreendedores por oportunidade ao longo das últimas três edições da pesquisa. A dos empreendedores por necessidade, ao contrário, mantémse abaixo dos 6\%, e chega a decair consideravelmente em 2008, apesar de essa queda ter-se revertido em 2009 - talvez em função, novamente, das incertezas econômicas, sobretudo nos três primeiros trimestres. De uma maneira geral, no entanto, parece haver indícios de que o empreendedorismo por necessidade está aos poucos cedendo espaço ao empreendedorismo por oportunidade no Brasil. Trata-se de uma boa notícia, cuja confirmação esperamos para as próximas edições da pesquisa.

TABELA 1 - EVOLUÇÃO DA TAXA
DE EMPREENDEDORES NASCENTES E NOVOS
(\% sobre a população de 18 a 64 anos)

\begin{tabular}{|lll}
\hline Ano & $\begin{array}{l}\text { Taxa de } \\
\text { Empreendedores Nascentes }\end{array}$ & $\begin{array}{l}\text { Taxa de } \\
\text { Empreendedores Novos }\end{array}$ \\
\hline 2001 & 9,23 & 4,98 \\
\hline 2002 & 5,68 & 8,46 \\
\hline 2003 & 6,51 & 6,90 \\
\hline 2004 & 4,98 & 8,88 \\
\hline 2005 & 3,15 & 8,20 \\
\hline 2006 & 3,50 & 8,62 \\
\hline 2007 & 4,29 & 8,72 \\
\hline 2008 & 2,93 & 9,29 \\
\hline 2009 & 5,78 & 9,75 \\
\hline
\end{tabular}

FONTE: PESQUISA GEM 